in the rates of chromosomes with lethals. The results agree then very well with those of Sävhagen on induced crossing-over.

As an explanation of her results, Sävhagen has proposed that primary spermatogonia at division are not always the source of one primary and one secondary spermatogonial cell, as suggested by Tihen ${ }^{3}$, but may divide into two primary or into two secondary gpermatogonia. Those which have divided into two primary spermatogonia may later divide in a similar manner into two primary or two secondary cells or they may follow the stem cell type of division into one primary and one secondary cell. These later divisions should occur at random and then it would be very possible that some of the mutant spermatogonia would disappear from the testes and some which remained could be the source of large clusters in later mating periods.

Another oxplanation of the results of Sävhagen and of this work could be that there is some kind of solection mechanism in the spermatogonial tissue. If so this should be reflected in the selective values of the heterozygotes of lethals which have been found following different occasions of irradiation and mating. In order to try to throw light on this problem persistency tests of different lethals which have been found in this experiment are now being carried out.

Institute of Genetics,

University of Stockholm.

${ }^{1}$ Khishin, A. F. E., Z. Ind. Abst., 87, 97 (1955).

a Muller, H. J., Proc. Second Intern. Conf. Geneva, 22, 313 (1958).

' Tihen, J. A., Amer. Nat., 80, 389 (1946).

\section{BUILDING RESEARCH}

\section{Bond of Galvanized Steel Reinforcement in Concrete}

Galvanizing is at present being advocated as a means of combating corrosion of reinforcing steel in concrete, and galvanized high-tensile wire is already being used extensively in strossed concrete structures. A survey of existing literature on this subject yielded littlo useful information, except that various investigators have reported widely divergent results, ofton in direct conflict.

Thus, Robinson ${ }^{1}$ showed that the average bond stress of $\frac{1}{2}$-in. galvanized steel bars in concrete, at failure, was 54 per cent of that of rusty bars. For 8 in. rods the figure is reduced to 41 per cent.

D. A. Lewis and J. A. P. Laurie (privato communication, i958), on the other hand, reported the bondstrength of $\frac{3}{8}$ in. galvanized reinforcernent and that of black or pickled steel, after 9 months' exposure, to be very similar.

Recent experience, during the preparation of prestressed concrete beams, has been equally confusing. Using a galvanized high tensile wire $A$ (coating weight $1.00 \mathrm{oz} . / \mathrm{sq}$. ft.) as prestressing reinforcement, very little bonding was obtained, the concrete immediately surrounding the wire being spongy. Extensive cracking occurred when external stress was released. Wire $B$, however, with only 0.5 oz. of galvanizing per sq. ft., did not show this tendency. Fig. 1 illustrates this.

Initial laboratory experiments indicated that, when pure zinc is immersed in Portland cement extract of $p \mathrm{H} 12 \cdot 8$, no hydrogen is liborated. As soon as a piece of clean steel is brought in contact with the pure zine

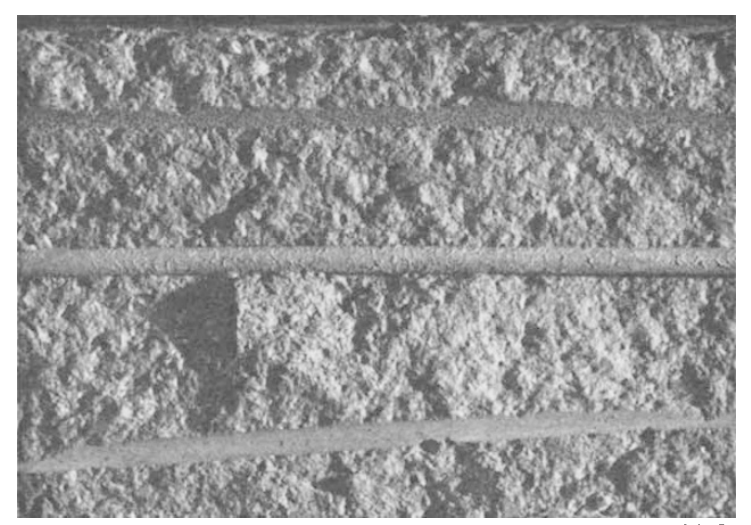

Fig. 1. Concrete in which galvanized steel wires are embedded. Top, Spongy concrete surrounding wire $A ;$ middle, wire $A$ in
position; bottom, normal concrete surrounding wire $B$

under these conditions, however, hydrogen is liberated cathodically or the steel.

From this it was deduced that iron, of relatively low hydrogen overpotential, exposed to wet fresh concrete, either as zinc-iron alloys or at imporfections in the zine coating of a galvanized rod, would lead to hydrogen evolution which would impair the bond. Tests were carried out to substantiate this theory.

Microscopic inspection of cross-sections of the wires $A$ and $B$ showed clearly that, while the outer layer of the galvanized coating on wire $B$, although thin, consists essentially of pure zinc, the coating on wire $A$ is comprised almost entirely of zinc-iron alloy.

Micro-hardness test results, together with microsection photographs, showed that the coating on the galvanized bars with a specified coating of $2.0 \mathrm{oz} / \mathrm{sq}$. ft. used by Lewis and Laurie in their experiments had a substantial outer layer consisting mainly of pure zinc. When embedded in concrete no loss of bond due to hydrogen liberation resulted, confirming their original results. When similar bars, which had previously been annezled at $400^{\circ} \mathrm{C}$. for $2 \mathrm{hr}$. to allow alloy-formation to extend to the coating surface, were placed in concrete, hydrogen was evolved with resultant disruption of the bond.

When the galvanizing on unannealed rods was removed by filing to expose steel at several points along their length and the rods embedded in concrete, hydrogen was evolved on the exposed steel surfaces. The surrounding concrete became porous with little bond to the exposed steel; the bond to intact galvanized surfaces remained unaffected.

Present indications are that, although the amount of gas liberated is sufficient to affect the bond, the galvanic cell between the galvanized surfaces and iron is rapidly polarized and hydrogen evolution ceases within I hr.

Thus, the adverse consequences of using galvanized reinforcement where alloys appear at the coating surface, having ungalvanized cut-ends, a damaged coating, or where it is used with ungalvanizod steel binding wire, are clearly evident. Specifying a minimum thicknoss of coating does not necessarily obviate the problem since, as has been shown, even a coating of $1.00 \mathrm{oz} / \mathrm{sq}$. ft. may have zinc-iron alloys extending to the surface.

Couneil for Scientific and Industrial Rescarch,

National Building Research Institute, Scientia, Protoria.

${ }_{2}^{2}$ Robinson, K. E., Cement and Concrete Assoc. Tech. Rep, TRA/220 (London, March 1956). 